\section{Development of a predictive model for the shelf-life of Atlantic mackerel (Scomber scombrus)}

\author{
Filippo Giarratana, ${ }^{1}$ Felice Panebianco, ${ }^{2}$ \\ Luca Nalbone, ${ }^{1}$ Graziella Ziino, ${ }^{1}$ \\ Davide Valenti, ${ }^{3,4}$ Alessandro Giuffrida ${ }^{1}$ \\ ${ }^{1}$ Department of Veterinary Science, \\ University of Messina; ${ }^{2}$ Department of \\ Veterinary Sciences, University of Turin, \\ Grugliasco; ${ }^{3}$ Department of Physics and \\ Chemistry, University of Palermo, \\ Group of Interdisciplinary Theoretical \\ Physics and CNISM, Palermo Unit; \\ ${ }^{4}$ CNR-IRIB, Consiglio Nazionale delle \\ Ricerche - Istituto per la Ricerca e \\ l'Innovazione Biomedica, Palermo, Italy
}

\section{Abstract \\ Despite its commercial value, the shelf-} life of the Atlantic mackerel (Scomber scombrus) during refrigerated storage was poorly investigated. In this regard, the Quality Index Method (QIM) was proposed as a suitable scoring system for freshness and quality sensorial estimation of fishery products. This study aims to develop a deterministic mathematical model based on dynamic temperatures conditions and a successive statistical analysis of the results obtained. This model will be exploited to predict the shelf-life of the Atlantic mackerel based on specific storage temperatures. A total of 60 fresh fishes were subdivided into two groups and respectively stored in ice for 12 days at a constant temperature of $1 \pm 0.5^{\circ} \mathrm{C}$ (Group A) and a fluctuating temperature ranging between 1 and $7^{\circ} \mathrm{C}$ (Group B). Microbiological analysis and sensory evaluation through the QIM were performed on each fish at regular time intervals. A critical value of $6 \mathrm{Log} \mathrm{cfu} / \mathrm{g}$ of spoilage bacteria (mainly psychotropic) associated with a significant decay of the sensorial characteristics was exceeded after 9 days of storage for Group A and 3 days for Group B. A reliable prediction of fish freshness was obtained by modelling the QIM as a function of the spoilage bacteria behaviour. A coefficient $\beta$ of correlation was determined to convert the spoilage bacteria load into a Quality Index score. The adoption of mathematical predictive models to assess microbial behaviour under different environmental conditions is an interesting tool for food industries to maximize production and reduce waste.

\section{Introduction}

The Atlantic mackerel (Scomber scombrus - Linnaeus 1758) is an epipelagic and mesodemersal species with a mean adult length of about $30 \mathrm{~cm}$. Scomber scombrus is widespread in cold and temperate areas, especially in the North Atlantic Ocean, eastern Atlantic, Black Sea and Mediterranean Sea (Collette and Nauen, 1983). In Italy, the main fishing area is the Adriatic Sea. The Atlantic mackerel has a relevant commercial value, and it is mainly traded fresh, frozen, smoked and canned. Despite the commercial relevance and the importance of this species in human nutrition, there are only a few studies concerning its shelf-life during refrigerated storage (Andrade et al., 1997). Instead, the effects of processing technologies on the quality and shelf-life of mackerel were studied more in-depth. The influence of smoking on the physicochemical and microbiological quality of mackerel has been investigated for a long time and are still the subject of numerous studies today (Kolodziejska et al., 2002; Popelka et al., 2021) while new preservative techniques have been proposed more recently such as hyperbaric cold storage (Otero et al., 2019) and the use of essential oils (Karoui and Hassoun, 2017). It is generally known that loss of freshness of fish is related to post-mortem biochemical, physicochemical and microbiological processes as well as of several extrinsic factors such as the handling onboard and land, and technological processing. These changes are appreciable in sensory terms and can be evaluated by sight, touch, smell and taste.

The Quality Index Method (QIM) is a scoring system for freshness and quality sensorial estimation of fishery products, developed by the Tasmanian Food Research Unit (Bremner, 1995) and, in the last decade, has been developed for several species and products (Calanche et al., 2020; Giuffrida et al., 2017; Tsironi et al., 2011). A range of demerit points is assigned to a set of characteristic attributes for several parameters; the scores are added up obtaining an overall sensory score, the Quality Index (QI).

Several authors have reported a linear correlation between the QI score and the time of storage in ice, providing a prediction of freshness for a given fishery product (Huidobro et al., 2000; Hyldig G, GreenPetersen, 2004). On this background, several mathematical models have been proposed for the seafood shelf-life prediction (Dalgaard, 1995; Giarratana et al., 2020; Ratkowsky et al., 1983).

In a previous study, we proposed a predictive approach to model the evolution of
Correspondence: Luca Nalbone, Department of Veterinary Science, University of Messina, Polo Universitario dell'Annunziata, 98168, Messina, Italy.

Tel.: +39.0906766889

E-mail: lnalbone@unime.it

Key words: Scomber scombrus, Quality Index Method, Spoilage bacteria, Predictive model.

Contributions: The authors contributed equally.

Conflict of interest: The authors declare no conflict of interest.

Funding: None.

Received for publication: 6 August 2021.

Accepted for publication: 12 November 2021.

This work is licensed under a Creative Commons Attribution-NonCommercial 4.0 International License (CC BY-NC 4.0).

(C) Copyright: the Author(s), 2022

Licensee PAGEPress, Italy

Italian Journal of Food Safety 2022; 11:10019

doi:10.4081/ijfs.2022.10019

Quality Index scores of Gilthead seabream (Sparus aurata) based on the prediction of spoilage microflora (Specific Spoilage Organisms - SSOs) (Giuffrida et al., 2013; Gram et al., 1987; Valenti et al., 2016). This model was validated against the QI scores derived by two different sets of temperatures and reproduced, with a good agreement, the observed data.

This work aims to apply the above model in its simplified form in order to predict the QI score evolution of Atlantic mackerel stored under two different temperature profiles.

\section{Materials and methods}

\section{Fish, storage conditions and sam-} pling plan

A batch of Atlantic mackerel (Scomber scombrus) consisting of 60 fishes (400$500 \mathrm{~g}$ ) was purchased from a local cold store, after 12 hours from harvest. The batch was divided into two groups: the first group ("Group A": 30 samples) was packed in expanded polystyrene boxes with perforated bottom, covered by a plastic film with ice flakes on top and stored at $1 \pm 0.5^{\circ} \mathrm{C}$ for 12 days (288 hours). The second group ("Group B": 30 samples) was packed as the first one but stored under a fluctuating temperature ranging from 1 to $7^{\circ} \mathrm{C}$ in 24 hours for 12 days (288 hours). Each box was 
refilled with ice approximately every 24 hours. In both groups, temperature (T) was monitored by three data loggers (FT 800, Econorma, Vendemmiano, Italy) placed in the gill chambers under the opercula of three different fishes, recording the $\mathrm{T}$ value every 8 minutes. Microbiological and sensorial evaluations were carried out after 0 , $72,144,216$ and 288 hours from the storage beginning, by sampling six fishes for each time interval. Microbiological assays were performed by sampling from each fish, with sterile instruments, dorsal skin, gills, and dorsal flesh. Dorsal flesh sample was obtained from the opposite side where the skin was sampled, rinsing the skin with $70 \%$ ethanol, and removing the flesh aseptically. Therefore, the sampling plan produced six growth curves of spoilage bacteria for each sampling site (skin - series "sk", gills - series "g" and flesh - series "f") for the two-sample series (Group A at $1 \pm 0.5^{\circ} \mathrm{C}$ and Group B under a fluctuating temperature profile).

\section{Microbiological analysis}

For microbiological analysis $10 \mathrm{~g}$ of dorsal skin, $5 \mathrm{~g}$ of gills and $20 \mathrm{~g}$ of dorsal flesh were separately transferred to a stomacher bag and homogenized for $60 \mathrm{~s}$ at 230 rpm by a stomacher (Stomacher ${ }^{\circledR} 400$ Circulator, International PBI s.p.a., Milan, Italy) with $0.1 \%$ peptone water, added with a ratio of $1: 9(\mathrm{w} / \mathrm{v})$. One $\mathrm{ml}$ from serial tenfold dilutions in $0.1 \%$ peptone water of the homogenized samples was plated, in duplicate, in Iron Agar (Lyngby) (Oxoid LTD., Basingstoke, Hampshire, England) (Gram et al., 1987) and incubated at $20^{\circ} \mathrm{C}$ for 3 days for the counts of SSOs. After 3 days of incubation black colonies were recorded as sulphide-producers, whereas white colonies were counted as sulphide non-producers.

A representative percentage of colonies, during each analysis session and for each group, was cultured on Trypticase Soy Agar (Biolife, Milano, Italy) at $30^{\circ} \mathrm{C}$ for 48 hours. In detail, $20 \%$ of both white and black colonies, if present, were selected from those grown in the plates, choosing the well-defined and isolated ones. These isolates were identified with matrix-assisted laser desorption ionization-time-of-flight mass spectrometry (MALDI-TOF MS) system by using VITEK MS (bioMérieux, Firenze, Italy) in association with SARAMIS software (Spectral ARchive and Microbial Identification System - Database version V4.12 - Software year 2013, bioMérieux, Firenze, Italy), according to the protocol described by Ziino et al. (2019).

A mix of each kind of sample (dorsal skin, gills, and dorsal flesh) at each time interval was analysed for $\mathrm{pH}$ value too (pHmeter HI90023CW - Hanna Instruments - with electrode Mettler Toledo InLab 427).

\section{Sensorial evaluation}

For sensorial evaluation, the QIM scheme developed by Andrade et al. (1997) for raw whole Atlantic mackerel was used with some modifications. The original QIM method considers parameters relating to "general appearance (0-8 demerits point)", "eyes (0-7 demerits point)", "gills (0-5 demerits point)", "abdomen (0-3 demerits point)", "peritoneum (0-2 demerits point)", "guts (0-2 demerits point)", "flesh (0-2 demerits point)" with a maximum of 29 demerit points. For the present study, in order to facilitate the construction of a predictive model according to the following section "Mathematical predictive model", it was rearranged into a maximum of 16 points (Table 1). The QIM scheme has been applied by an expert panel of ten people, previously trained in developing and using fish QIM schemes.

\section{Mathematical predictive model}

To construct the predictive model, QIM parameters were grouped in three main categories: $Q I M_{S k}$, including scores for general "appearance" and "eyes" (0 - 6 demerit points); $Q_{I M}$ related to gills scores $(0-4$ demerit points); $Q I M_{F}$ that considers the score assigned to the flesh, abdomen and gut evaluation ( $0-6$ demerit points). $Q I M_{S k}, Q I M_{G}$ and $Q I M_{F}$ were associated with the bacterial counts on Iron Agar of skin, gills and flesh, respectively; therefore, for the dynamic prediction of each QIM category as a function of the time was used the following general differential equation:

$$
\frac{d Q I M_{(s k-g-f)}}{d t}=\frac{d N_{(s k-g-f)}}{d t} \beta_{(s k-g-f)}
$$

where $N$ is the concentration ( $\log \mathrm{cfu} / \mathrm{g}$ ) of spoilage bacteria at time $t(\mathrm{~h}) ; b$ is the coefficient that translates bacterial concentration into demerit points.

According to the Baranyi and Roberts

Table 1. Modified version of the QI scheme by Andrade et al. (1997) for Scomber scombrus.

\begin{tabular}{|c|c|c|}
\hline Parameters & Characteristic & Demerit point \\
\hline \multicolumn{3}{|c|}{ General appearance } \\
\hline Surface appearance & $\begin{array}{l}\text { Strong blue; traslucent slime } \\
\text { Loss of bright colours; pale golden tinge; slime slightly cloudy } \\
\text { Golden tinge overall all body; milky/yellowish slime }\end{array}$ & $\begin{array}{l}0 \\
1 \\
2\end{array}$ \\
\hline \multicolumn{3}{|c|}{ Eyes } \\
\hline Pupil & $\begin{array}{l}\text { Shiny jet-black/blue } \\
\text { Black, cloudy (in the centre) } \\
\text { Grey }\end{array}$ & $\begin{array}{l}0 \\
1 \\
2\end{array}$ \\
\hline Cornea & $\begin{array}{l}\text { Convex } \\
\text { Plane } \\
\text { Concave }\end{array}$ & $\begin{array}{l}0 \\
1 \\
2\end{array}$ \\
\hline \multicolumn{3}{|c|}{ Gills } \\
\hline Colour & $\begin{array}{l}\text { Uniformly red with blood, slime translucent } \\
\text { Brownish with slime } \\
\text { Dark brown with abundant slime }\end{array}$ & $\begin{array}{l}0 \\
1 \\
2\end{array}$ \\
\hline Smell & $\begin{array}{l}\text { Fresh, seaweedy } \\
\text { Neutral } \\
\text { Fish - ammonia }\end{array}$ & $\begin{array}{l}0 \\
1 \\
2\end{array}$ \\
\hline \multicolumn{3}{|c|}{ Abdomen } \\
\hline Postgill (belly-burst) & $\begin{array}{l}\text { Firm } \\
\text { Stretchmarks, soft } \\
\text { Torn }\end{array}$ & $\begin{array}{l}0 \\
1 \\
2\end{array}$ \\
\hline \multicolumn{3}{|c|}{ Guts } \\
\hline Appearance & $\begin{array}{l}\text { Normal and bright } \\
\text { Slight decomposition and less bright } \\
\text { Strong decomposition, dull }\end{array}$ & $\begin{array}{l}0 \\
1 \\
2\end{array}$ \\
\hline \multicolumn{3}{|c|}{ Flesh } \\
\hline Texture and colour & $\begin{array}{l}\text { Very firm and fresh bloom, bright } \\
\text { Less firm, less bright } \\
\text { Soft, opaque }\end{array}$ & $\begin{array}{l}0 \\
1 \\
2\end{array}$ \\
\hline
\end{tabular}

Total demerit points 0-16. 
(1994) model, the bacterial concentration $N$ at time $t$ is generically expressed as follows:

$$
\frac{d N}{d t}=\mu_{\max } N \frac{Q}{1+Q}\left(1-\frac{N}{N_{\max }}\right)
$$

Here $\mu_{\max }\left(\mathrm{h}^{-1}\right)$ is the maximum specific growth rate and $N_{\max }(\mathrm{cfu} / \mathrm{g})$ is the theoretical maximum population density of bacterial species under monospecific growth conditions; $Q$ represents the physiological state of the species and, as expressed in Eqs. (3ab), allows to calculate the Lag-time $(\lambda)$ duration (hours) (Baranyi and Roberts, 1994):

$$
\begin{aligned}
& \lambda=\frac{-\ln \alpha(t)}{\mu_{\max }(t)} \\
& \alpha(t)=\frac{Q(t)}{1+Q(t)}
\end{aligned}
$$

Equation [2] was solved by the introduction of a secondary model (equation [4]) for psychrotolerant pseudomonads (Martinez-Rios et al., 2016), which are recognized as the most important spoilage bacterial population for whole fish, in order to calculate the $\mu_{\max }$ according to environmental observed parameters ( $\mathrm{T}$ profile and $\mathrm{pH}$ ).

$$
\mu_{\max }=\mu_{\text {ref } 25^{\circ} C}\left(\frac{T-T_{\min }}{T_{\text {ref }}-T_{\min }}\right)^{2}\left(1-10^{\left(p H_{\min }-p H\right)}\right)
$$

According to Martinez-Rios et al. (2016), $\mu_{\mathrm{ref} 25^{\circ} \mathrm{C}}=0.62 ; T_{\min }=-7.01 ; p H_{\text {min }}=$ 4.85. The complete model (equation [2] and [4]) has been used for fitting each growth curve to calculate $Q_{0}, N_{\max }$ and to evaluate the predictive performance. After that, the complete predictive model has been incorporated into equation [1] which was solved against the mean observed microbiological data for each series (series "sk", series "g", series "f") and both temperature profiles. Afterwards, a second fitting procedure has been applied for calculating the coefficients $b_{s k}, b_{g}$ and $b_{f}$ in order to predict QIM values.

Model was numerically solved by Eulero method, and the "Solver" function of Microsoft Excel (Office 365) was used for each growth curve of each data set. The Root Mean Square Error (RMSE) was used to evaluate the goodness of our model comparing the predicted values and the observed ones.

\section{Results}

\section{Microbiological and sensorial analy- sis}

The count of spoilage bacteria on Iron Agar together with the related temperature profile, appeared always higher for skin samples (Series sk) than gills and flesh (Figure 1). This difference was more evident in samples of Group B (fluctuating temperature profile) where the critical value of $\log 6 \mathrm{cfu} / \mathrm{g}$ was exceeded after 3 days of storage while for Group A $\left(1 \pm 0.5^{\circ} \mathrm{C}\right)$ this value was approximatively observed after 9 days. Concerning the "g" and "f" series, the growth rate of the spoilage bacteria observed in the samples of group A was lower than in group B as can be seen by the always lower microbial loads during each analysis session (Figure 1). For both Groups, series "f" showed always the lowest bacterial load and the microbial counts of flesh samples of Group A never exceeded Log $6 \mathrm{cfu} / \mathrm{g}$.

Concerning these bacterial populations, overall, the MALDI-TOF identifies the $83.0 \%$ of strains as belonging to genera
Pseudomonas spp. (61.8\%) and Shewanella putrefaciens $(21.2 \%)$. The remaining percentage of colonies belonged to genera Citrobacter spp. (9.6\%) and Proteus spp. $(7.4 \%)$. In particular, the $100 \%$ of white colonies were Pseudomonas spp., whereas the $55.5 \%$ of the black colonies were Shewanella putrefaciens, the $25.13 \%$ were Citrobacter spp. and $19.36 \%$ were Proteus spp.

Concerning the QIM scores, as Fig. 2a shows, QIM ${ }_{\text {TOT }}$ scores of Group A samples had an increase slower than Group B samples. Furthermore, the former did not reach the maximum score (16) within 12 days conversely of Group B samples which reached the highest demerit score after 10 days. Figures $2 \mathrm{~B}, 2 \mathrm{~B}$ and $2 \mathrm{D}$, where the trend of single components of $\mathrm{QIM}_{\mathrm{TOT}}$ scores $\left(\mathrm{QIM}_{\mathrm{Sk}}, \mathrm{QIM}_{\mathrm{G}}\right.$ and $\left.\mathrm{QIM}_{\mathrm{F}}\right)$ are shown, stress the aforementioned differences between Group A and B.

\section{Predictive model}

The complete predictive model obtained by incorporating equation [4] into equation [2] has allowed calculating the average of basic parameters such as $\mathrm{Q}_{0}$ and $\mathrm{N}_{\max }$; particularly, the former was always set at $0.170 \pm 0.03$ while the $\mathrm{N}_{\max }$ mean values have been $\log 9.0 \pm 0.3 \mathrm{cfu} / \mathrm{g}, \log 7.7 \pm 0.25$ $\mathrm{cfu} / \mathrm{g}$ and $\log 6.25 \pm 0.2 \mathrm{cfu} / \mathrm{g}$ respectively for series "sk", "g" and "f". The complete model produced a prediction for each mean growth curve of each series, in good agreement with the observed ones (Figure 3). Particularly, the RMSE values for Group A (samples refrigerated in ice) have been $0.42,0.32$ and 0.61 respectively for series "sk", "g" and "f", while for Group B samples the RMSE values have been 0.84, 0.56 and 0.29 respectively for series "sk", "g" and "f". These predictions were used for calculating beta values of equation [1] by a fitting procedure. The obtained values,
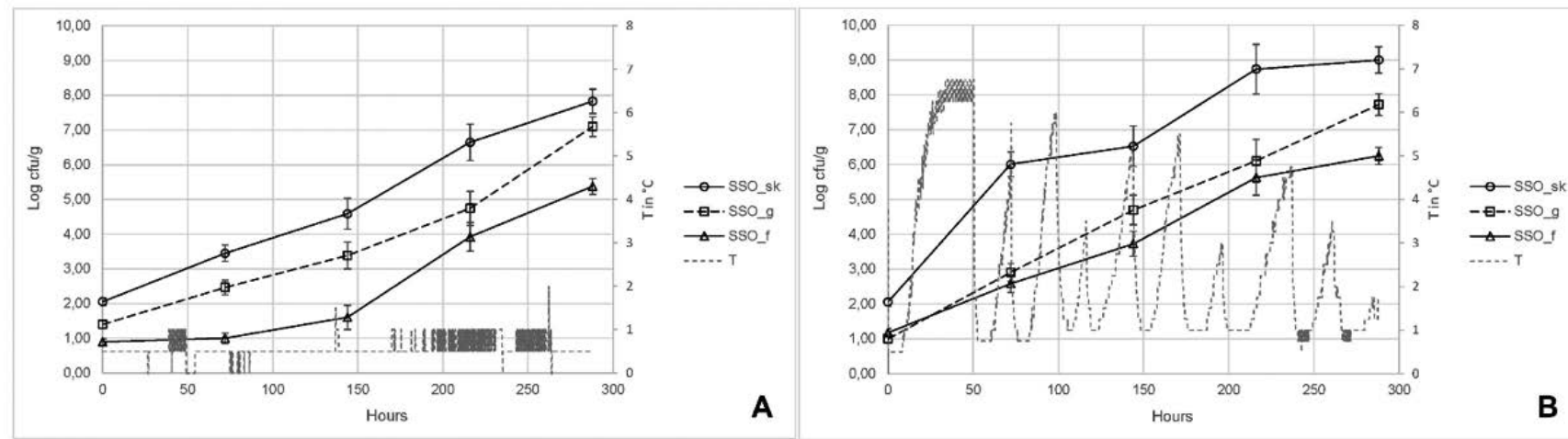

Figure 1. Count of spoilage bacteria at three different sampling sites - skin (sk), gills (g) and flesh (f) - in specimens of Scomber scombrus stored at different temperature profiles: (A) $1 \pm 0.5^{\circ} \mathrm{C}$ for 12 days; (B) fluctuating temperature ranging from 1 to $7^{\circ} \mathrm{C}$ in 24 hours for 12 days. 
valid for both temperature profiles, were $0.113 \pm 0.06$ for $\beta_{s k}, 0.090 \pm 0.04$ for $\beta_{g}$ and $0.150 \pm 0.05$ for $\beta_{f}$. The prediction of QIM ${ }_{\text {TOT }}$ values is shown in Figure 4; also, in this case, the predictions appear in good agreement with the observed trend and highlight that the model accounts correctly for experimental data also under fluctuating temperature conditions too.

\section{Discussions and conclusions}

Predictive food microbiology allows an increasingly pragmatic approach to managing food safety and quality. Here we presented a study carried out by varying environmental parameters such as the temperature and performing successively a statistical analysis on the results obtained. The deterministic model herein implemented can be suitable operational support in the food industry considering the increasing demand for rapid methods for determining the shelf-life of the fresh fish. Indeed, predicting microbial behaviour and associated sensory variations under different environmental conditions supports managerial decisions in establishing or running a man- ufacturing operation as well as assessing the impact of process deviations on microbiological safety and product quality (Doyle et al., 2019). Furthermore, with a view to sustainable development, the implemented model could be useful for maximizing production and reducing waste (Kibler et al., 2018).

In the present study, the mathematical model was developed to reliably predict the shelf-life of the Atlantic mackerel, based on different storage temperatures. The same mathematical model was previously proposed to model the storage life of Gilthead Seabream obtaining performing results (Giuffrida et al., 2013; Gram et al., 1987; Valenti et al., 2016). Fresh seafood is characterized by a short shelf-life which mostly depends on microbial activity (Arab et al., 2020; Ozogul et al., 2020; Trabelsi et al., 2019). The metabolism of certain specific spoilage bacteria leads to the formation of products responsible for off-flavors, offodors and color variations once reached certain loads (Cheng and Sun, 2015). In this regard, according to other studies (Giuffrida et al., 2013; Huss, 1995), the results of the present manuscript demonstrate that most relevant quality modifications of the whole refrigerated Atlantic mackerel are especial- ly explained by the bacterial growth on skin and gills which are always, as well known, more contaminated than the flesh. Moreover, the mucus of these sites is rich in proteins, glucides and lipids as well as in several ammonia excreta which can be metabolised in off-flavour substances by bacteria (Gram and Huss, 1996; Trabelsi et al., 2021).

Most of the bacterial population detected in this study, belonged to genera Pseudomonas and Shewanella and critical values of $\log 6 \mathrm{cfu} / \mathrm{g}$ were observed in conjunction with a decay of the organoleptic qualities. These isolations are in agreement with other results (Gram and Huss, 1996; Koutsoumanis and Nychas, 2000) concerning fish caught or harvested in temperate waters and explain the kind of spoilage of the Atlantic mackerel, which is characterized by the development of offensive fishy, rotten, $\mathrm{H}_{2} \mathrm{~S}$-off-odours and -flavours. This sensory impression is distinctly different for some tropical fish and freshwater fish, where fruity, sulphydryl off-odours and flavours are more typical (Gram and Huss, 1996).

As highlighted in the present study, the evaluation of the sensory modifications in fresh mackerel by the QIM showed satisfac-
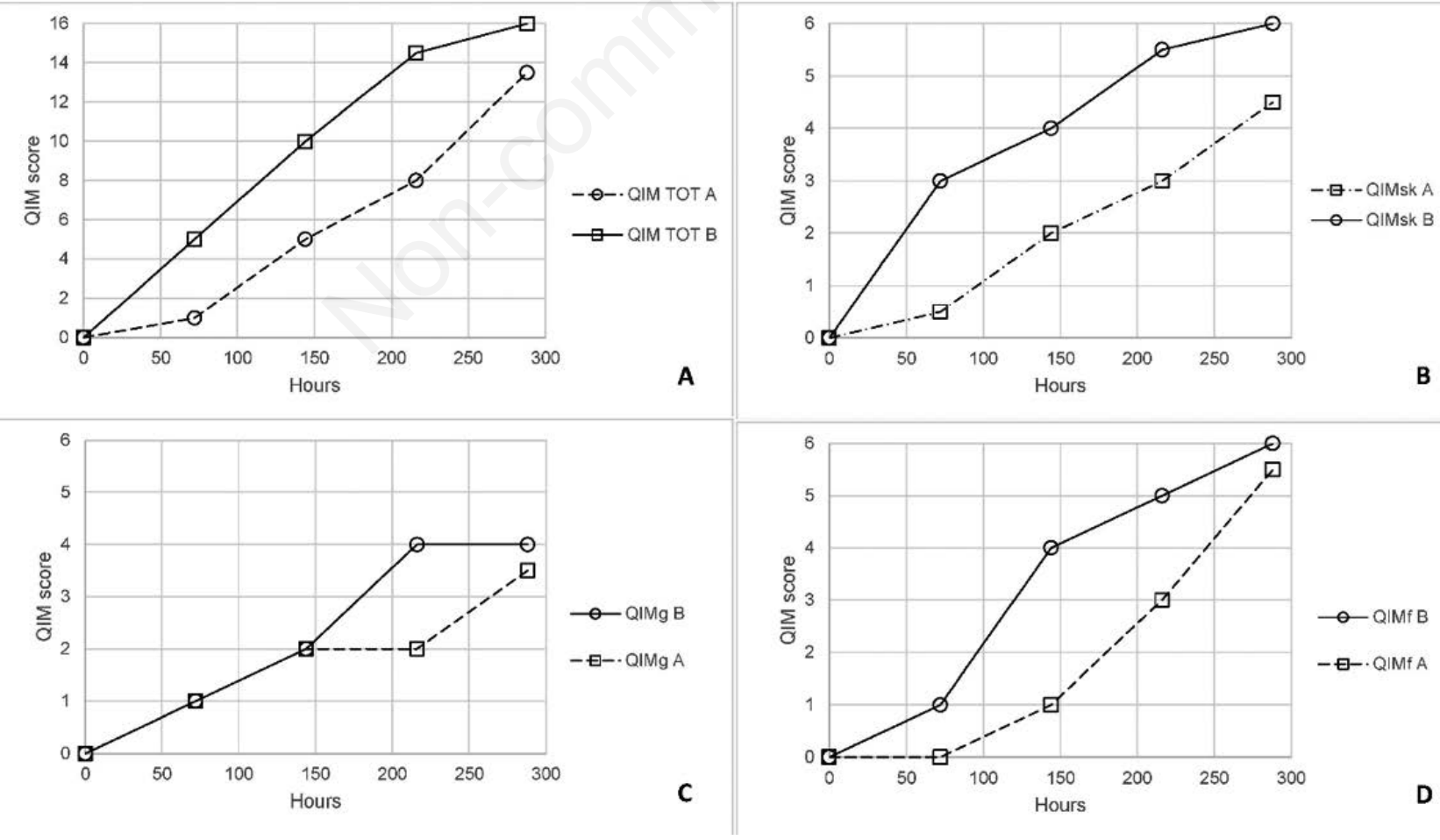

$-も-$ QIMf A

C

Figure 2. QIM trend for Group A $\left(1 \pm 0.5^{\circ} \mathrm{C}\right)$ and Group B (fluctuating temperature profile): A trend of total QIM score $(\mathrm{QIM}$ TOT); B trend of QIM related to skin (QIMsk); C trend of QIM related to gills (QIMg); D trend of QIM related to flesh (QIMf). 
tory correlations with the determination of the storage time. Not surprisingly, numerous schemes have been implemented over the years for several other species of blue fish both whole fish such as Mediterranean anchovies (Engraulis encrasicholus) (PonsSánchez-Cascado et al., 2006), herring (Clupea harengus L.) (Nielsen and Hyldig, 2004) and horse mackerel (Trachurus mediterraneus) (Mbarki et al., 2009) and fillets or portions of fish such as fresh yellowfin tuna (Thunnus albacares) steaks (Alexi et al., 2021). However, if on one hand the QIM is suitable for detecting trends in sensory quality during the shelflife, on the other hand, this method mixes subjective and objective sensory evaluations, requires trained and experienced panellists and it does not provide information on the remaining shelf life by itself.

The observed and predicted time for the rejection of the whole fish under refrigerated storage is similar to those reported in previous studies (Karoui and Hassoun, 2017; Svanevik and Lunestad, 2011). Considering a possible cause-effect relationship between data obtained by the sensory evaluation and the microbiological analysis, the achieved results were fitted to a differential equation in which QI score is expressed as a function of the concentration of specific spoilage bacteria. A coefficient $\beta$ of correlation was determined to relate the spoilage bacteria load with the QI scores. The constant value of $\beta$ allows evaluating the fish freshness as the microbial concentration changes under different temperatures and storage conditions. The developed predictive model was capable of reliably predicting the shelf-life of Atlantic mackerel under isothermal and fluctuating temperature storage conditions. However, certain aspects of population kinetics such as lag phase and growth rate are difficult to predict especially under dynamic conditions and even more in real food where several factors need to be considered in addition to the temperature variation (Giarratana et al., 2020). The environmental parameters that influence microbial behaviour are several and include the combined effects of intrinsic and extrinsic factors (Giuffrida et al., 2008; Giuffrida et al., 2017). Interaction between groups of microorganisms and several physicochemical properties of the substrate needs to be considered for a reliable prediction of a proper shelf-life. The pro-
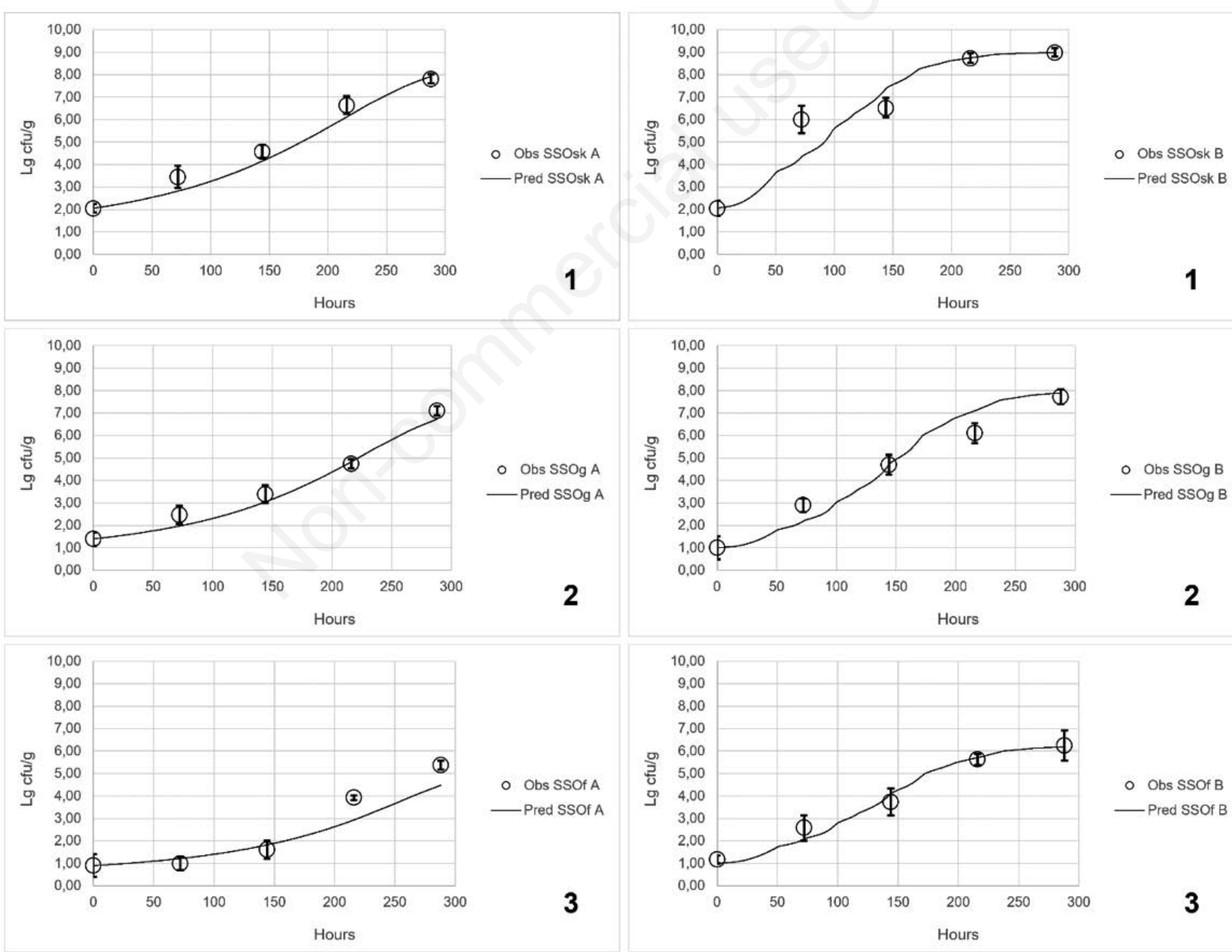

- Obs SSOf B

—Pred SSOf B

3

Hours

Figure 3. Observed growth of spoilage bacteria (Obs SSO) and related predictions (Pred SSO) at three different sampling sites - (1) skin (sk), (2) gills (g) and (3) flesh (f) - in specimens of Scomber scombrus stored at different temperature profiles: (A) $1 \pm 0.5^{\circ} \mathrm{C}$ for 12 days; (B) fluctuating temperature ranging from 1 to $7^{\circ} \mathrm{C}$ in 24 hours for 12 days. 


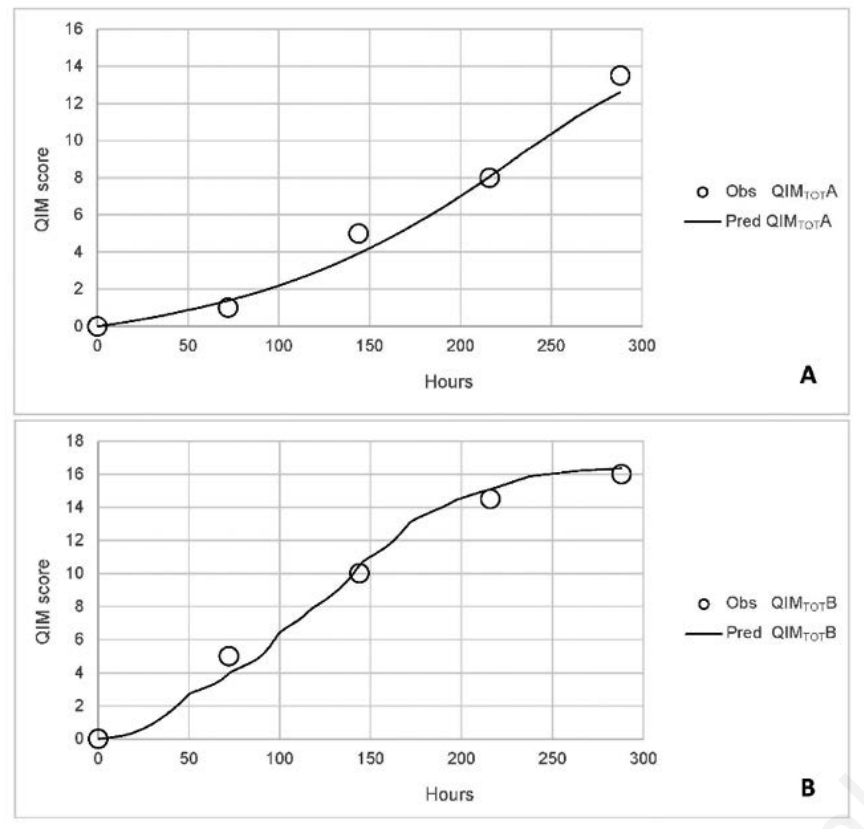

Figure 4. Observed total mean QIM values $\left(\right.$ Obs QIM $\left._{\mathrm{TOT}}\right)$ and related predictions (Pred QIMTOT) at three different sampling sites in specimens of Scomber scombrus stored at different temperature profiles: (A) $1 \pm 0.5^{\circ} \mathrm{C}$ for 12 days; (B) fluctuating temperature ranging from 1 to $7^{\circ} \mathrm{C}$ in 24 hours for 12 days.

posed model can be considered as an effective tool for the improvement of quality management within the fish supply and distribution chain. This shelf-life study provides a time-temperature relationship useful to determine the quality decay during some stages of the Atlantic mackerel commercial life. Further studies are desirable to improve the proposed mathematical model. It could be thought of inserting new equations which allow to consider and reproduce the time behaviour of other environmental variables as well as to evaluate a probabilistic approach in which variations in environmental parameters are taken into account.

\section{References}

Alexi N, Hvam J, Lund BW, Nsubuga L, de Oliveira Hansen RM, Thamsborg K, Lofink F, Byrne DV, Leisner J.J., 2021. Potential of novel cadaverine biosensor technology to predict shelf life of chilled yellowfin tuna (Thunnus albacares). Food Control 119:107458.

Andrade A, Nunes ML, Batista I, 1997. Freshness quality grading of small pelagic species by sensory analysis. In: Ólafsdóttir G, Luten J, Dalgaard P, Careche M, Verrez-Bagnis V, Martinsdóttir E, Heia K, eds. Methods to determine the freshness of fish in research and industry. Proceedings of the Final Meeting of the Concerted Action "Evaluation of Fish Freshness", AIR3CT94 2283, Nantes Conference, November 12-14 1997, International Institute of Refrigeration, Paris, France, pp 333-338.

Arab S, Nalbone L, Giarratana F, Berbar A, 2020. Occurrence of Vibrio spp. along the Algerian Mediterranean coast in wild and farmed Sparus aurata and Dicentrarchus labrax. Vet World 13:1199-208.

Baranyi J, Roberts TA, 1994. A dynamic approach to predicting bacterial growth in food. Int J Food Microbiol 23:27794.

Bremner HA, 1985. A convenient easy to use system for estimating the quality of chilled seafood. Fish Proc Bull 75.

Calanche J, Pedrós S, Roncalés P, Beltrán JA, 2020. Design of Predictive Tools to Estimate Freshness Index in Farmed Sea Bream (Sparus aurata) Stored in Ice. Foods 9:69.

Cheng JH, Sun DW, 2015. Rapid and noninvasive detection of fish microbial spoilage by visible and near infrared hyperspectral imaging and multivariate analysis. LWT- Food Sci Technol 62:1060-8.

Collette BB, Nauen CE, 1983. FAO Species
Catalogue. Vol. 2, Scombrids of the World. An Annotated and Illustrated Catalogue of Tunas, Mackerels, Bonitos and Related Species Known to Date. FAO Fish. Synop. 125.

Dalgaard P, 1995. Modelling of microbial activity and prediction of shelf life of packed fresh fish. Int J Food Microbiol 19:305-18.

Doyle MP, Diez-Gonzalez F, Hill C, 2019. Food microbiology: fundamentals and frontiers. 5th ed. John Wiley \& Sons, Washington, DC, USA, pp. 993.

Giarratana F, Nalbone L, Ziino G, Giuffrida A, Panebianco F, 2020. Characterization of the temperature fluctuation effect on shelf life of an octopus semi-preserved product. Ital J Food Saf 9.

Giuffrida A, Giarratana F, Valenti D, Muscolino D, Parisi R, Parco A, Marotta SM, Ziino G, Panebianco A, 2017. A new approach to predict the fish fillet shelf-life in presence of natural preservative agents. Ital J Food Saf 6:6768.

Giuffrida A, Valenti D, Giarratana F, Ziino G, Panebianco A, 2013. A new approach to modelling the shelf life of Gilthead seabream (Sparus aurata). Int J Food Scie Technol 48:1235-42.

Giuffrida A, Ziino G, Valenti D, Donato G, Panebianco A, 2008. Application of an 
interspecific competition model to predict the growth of Aeromonas hydrophila on fish surfaces during the refrigerated storage. arXiv preprint arXiv:0811.2662.

Gram L, Huss HH, 1996. Microbiological spoilage of fish and fish products. Int $\mathrm{J}$ Food Microbiol 33:121-37.

Gram L, Trolle G, Huss HH, 1987. Detection of specific spoilage bacteria from fish stored at low $\left(0^{\circ} \mathrm{C}\right)$ and high $\left(20^{\circ} \mathrm{C}\right)$ temperatures. Int $\mathrm{J}$ Food Microbiol 4:65-72.

Huidobro A, Pastor A, Tejada M, 2000. Quality Index Method developed for Raw Gilthead Seabream (Sparus aurata). J Food Scie 65:1202-5.

Huss HH, 1995. Quality and quality changes in fresh fish. FAO Fisheries Technical Paper 348:130-1.

Hyldig G, Green-Petersen DMB, 2004. Quality Index Method - An objective tool for determination of sensory quality. J Aquat Food Prod Technol 13:7180.

Karoui R, Hassoun A, 2017. Efficiency of rosemary and basil essential oils on the shelf-life extension of Atlantic mackerel (Scomber scombrus) fillets stored at $2^{\circ} \mathrm{C}$. J AOAC Int 100:335-44.

Kibler KM, Reinhart D, Hawkins C, Motlagh AM, Wright J, 2018. Food waste and the food-energy-water nexus: a review of food waste management alternatives. Waste Manag 74:52-62.

Kołodziejska I, Niecikowska C, Januszewska E, Sikorski Z, 2002. The Microbial and Sensory Quality of Mackerel Hot Smoked in Mild Conditions. LWT- Food Sci Technol 35:87-92.

Koutsoumanis K, Nychas GJE, 2000. Application of a systematic experimental procedure to develop a microbial model for rapid fish shelf-life predictions. Int J Food Microbiol 60:171-84.
Martinez-Rios V, Østergaard BN, Gkogka E, Sand RP, Dalgaard P, 2016. Modelling and predicting growth of psychrotolerant pseudomonads in milk and cottage cheese. Int $\mathrm{J}$ Food Microbiol 216:110-20.

Mbarki R, Sadok S, Barkallah I, 2009. Quality changes of the Mediterranean horse mackerel (Trachurus mediterraneus) during chilled storage: The effect of low-dose gamma irradiation. 78: Radiat. Phys Chem 288-92.

Nielsen D, Hyldig G, 2004. Influence of handling procedures and biological factors on the QIM evaluation of whole herring (Clupea harengus L.). Food Res Int 37:975-83.

Otero, L., Pérez-Mateos, M., Holgado, F., Márquez-Ruiz, G., \& López-Caballero, M. E. (2019). Hyperbaric cold storage: Pressure as an effective tool for extending the shelf-life of refrigerated mackerel (Scomber scombrus, L.). Innov Food Sci Emerg Technol 51:41-50.

Ozogul Y, Boğa EK, Akyol I, Durmus M, Ucar Y, Regenstein JM, Köşker AR, 2020. Antimicrobial activity of thyme essential oil nanoemulsions on spoilage bacteria of fish and food-borne pathogens. Food Biosci 36:100635.

Pons-Sánchez-Cascado S, Vidal-Carou MC, Nunes ML, Veciana-Nogues MT, 2006. Sensory analysis to assess the freshness of Mediterranean anchovies (Engraulis encrasicholus) stored in ice. Food control 17:564-9.

Popelka P, Šuleková M, Jevinová P, Semjon B, Hudáková T, Klempová T, Čertík M, Roba P, Várady, M, 2021. Influence of smoking and packaging methods on physicochemical and microbiological quality of smoked mackerel (Scomber scombrus). Acta Vet Brno 90:117-24.

Ratkowsky DA, Lowry RK, Mcmeekin TA, Stokes AN, Chandler RE, 1983. Model for bacterial cultures growth rate throughout the entire biokinetic temperature range. J Bacteriol 154:1222-6.

Svanevik CS, Lunestad BT, 2011. Characterisation of the microbiota of Atlantic mackerel (Scomber scombrus). Int J Food Microbiol 151:164-70.

Trabelsi N, Nalbone L, Di Rosa AR, Ed-Dra A, Nait-Mohamed S, Mhamdi R, Giuffrida A, Giarratana F, 2021. Marinated Anchovies (Engraulis encrasicolus) Prepared with Flavored Olive Oils (Chétoui cv.): Anisakicidal Effect, Microbiological, and Sensory Evaluation. Sustainability 13:5310.

Trabelsi N, Nalbone L, Marotta SM, Taamali A, Abaza L, Giarratana F, 2019. Effectiveness of five flavored Tunisian olive oils on Anisakis larvae type 1: application of cinnamon and rosemary oil in industrial anchovy marinating process. J Sci Food Agric 99:4808-15.

Tsironi T, Stamatiou A, Giannoglou M, Velliou E, Taoukis PS, 2011. Predictive modelling and selection of time temperature integrators for monitoring the shelf life of modified atmosphere packed gilthead seabream fillets. LWT 44:1156-63.

Valenti D, Denaro G, Giarratana F, Giuffrida A, Mazzola S, Basilone G, Aronica S, Bonanno A, Spagnolo B, 2016. Modelling of sensory characteristics based on the growth of food spoilage bacteria. Math Model Nat Phenom 11:119-36.

Ziino G, Marotta SM, Giarratana F, Giuffrida A and Panebianco F, 2019. Reliability Evaluation of MALDI-TOF MS Associated with SARAMIS Software in Rapid Identification of Thermophilic Campylobacter Isolated from Food. Food Anal Methods 12:1128-32. 